\title{
ANALISIS NILAI TAMBAH PISANG NANGKA (Musa paradisiaca,L) (Studi Kasus di Perusahaan Kripik Pisang Krekes di Loji, Wilayah Bogor)
}

\author{
Eka H Purnama $^{1}$, I. Novita ${ }^{1 \mathrm{a}}$, A. Arsyad ${ }^{1}$ \\ ${ }^{1}$ Jurusan Agribisnis, Fakultas Pertanian Universitas Djuanda Bogor \\ Jalan Tol Ciawi No. 1 Kotak Pos 35 Bogor 16720 \\ a'Korespondensi: Ita Novita, Telepon: 0817400272, E-mail: novitazulfa@ yahoo.co.id;
}

\begin{abstract}
ABSTRAK
Tujuan penelitian ini untuk menganalisis nilai tambah pisang pada industri kecil (rumah tangga) padaperusahaan keripik pisang KREKES, dan menganalisis penerimaan dan keuntungan keripik pisang pada perusahaan KREKES. Penelitian ini dilakukan di UKM kripik pisang "KREKES" yang berlokasi di Kelurahan Loji, Kecamatan Bogor Barat, Kota Bogor, Jawa Barat. Analisis nilai tambah pisang untuk memproduksi keripik pisang menggunakan metode Hayami (1987). Diperoleh kesimpulan bahwa besarnya nilai tambah industri keripik pisang pada perusahaan Krekes adalah sebesar Rp.2.630,tingkat keuntungan 85,74 persen dengan nilai keuntungan sebesar Rp.2.255.
\end{abstract}

Kata kunci: Industri Kecil, Nilai Tambah

\section{PENDAHULUAN}

Indonesia merupakan negara berkembang yang sedang menuju ke arah industri maju sehingga proses perubahan sektor pertanian ke sektor industri tidak dapat dihindarkan, namun peran sektor pertanian sebagai pendukung dari sektor industri mutlak diperlukan sebagai penyeimbang struktur ekonomi. Pembangunan ekonomi Indonesia yang seharusnya dikembangkan adalah industri manufaktur agro (agroindustri). Pembangunan agroindustri dapat dikatakan merupakan kelanjutan dari pembangunan pertanian, apabila pembangunan pertanian berhasil maka pembangunan agroindustri pun berhasil, begitupun sebaliknya, apabila pembangunan pertanian gagal, maka pembangunan agroindustri pun sulit untuk berkembang (Soekartawi,2000).

Industri kecil merupakan usaha ekonomi yang tersebar di wilayah Indonesia, sebagian besar dikelola oleh masyarakat golongan ekonomi lemah yang membawa misi dalam bentuk pemerataan kesempatan kerja dan kesempatan berusaha. Sektor industri kecil menjadi salah satu alternatif pekerjaan, karena karakteristik yang dimilikinya, seperti aktivitas ekonominya, tidak hanya didasarkan pada kesempatan berinvestasi, tetapi lebih didasarkan pada dorongan untuk menciptakan kesempatan bagi dirinya sendiri.

Menurut Hicks (1995), agroindustri adalah kegiatan dengan ciri : (a) meningkatkan nilai tambah, (b) menghasilkan produk yang dapat dipasarkan atau digunakan atau dimakan, (c) meningkatkan daya simpan, dan (d) menambah pendapatan dan keuntungan produsen. Pengembangan agroindustri di Indonesia mencakup berbagai aspek, diantaranya menciptakan nilai tambah, menciptakan lapangan kerja, meningkatkan penerimaan devisa, memperbaiki pemerataan pendapatan, bahkan mampu 
menarik pembangunan sektor pertanian sebagai sektor penyedia bahan baku.

Industri makanan dan minuman menawarkan berbagai jenis produk makanan yang dapat dipilih oleh konsumen, salah satunya yaitu kripik pisang. Keripik pisang adalah makanan ringan yang paling banyak diproduksi dan diperdagangkan di Indonesia. Hal ini bisa dimaklumi, karena pisang juga merupakan buah yang paling banyak dibudidayakan dan dikonsumsi oleh masyarakat Indonesia. Selain itu, pisang juga merupakan buah tanpa musim, sehingga agroindustri keripik pisang bisa berlangsung sepanjang tahun tanpa berhenti. Namun pada musim kemarau, produksi pisang tidak sebanyak pada musim penghujan, sehingga para perajin keripik sering kesulitan bahan baku (Foragri.2011).

Bogor sebagai salah satu daerah sentra produksi industri kripik pisang di wilayah Jawa Barat, memiliki prospek yang cukup baik dalam pengembangannya, tingginya mobilitas penduduk di Bogor yang disebabkan berdekatan dengan pusat pemerintahan kota Jakarta menyebabkan semakin besarnya segmen pasar yang dapat dimasuki oleh suatu produk makanan jadi yang praktis untuk dikonsumsi.

Industri pangan memiliki potensi untuk terus berkembang dengan meningkatkan nilai tambahnya. Nilai tambah pengolahan komoditi pertanian merupakan imbalan bagi produsen berupa keuntungan, dengan keuntungan yang diperoleh maka produsen memiliki modal untuk dapat menjaga kesinambungan aktivitas dan pengembangan usahanya. Oleh karena itu nilai tambah yang diperoleh perlu didistribusikan dengan baik sehingga dapat meningkatkan produktivitas faktor-faktor

Berdasarkan uraian di atas, maka permasalahan yang akan dikaji dalam penelitian ini adalah: Berapa besar nilai tambah yang diperoleh dari pengolahan pisang menjadi produk kripik pisang, dan berapa besar tingkat keuntungan yang diterima produsen kripik pisang? Berdasarkan permasalahan di atas, maka tujuan penelitian ini untuk : menganalisis nilai tambah pisang pada industri rumah tangga pada KREKES, dan menganalisis penerimaan dan keuntungan keripik pisang pada perusahaan KREKES

\section{BAHAN DAN METODE}

\section{Lokasi dan Waktu Penelitian}

Penelitian ini dilakukan di UKM kripik pisang "KREKES" yang berlokasi di Kelurahan Loji, Kecamatan Bogor Barat, Kota Bogor, Jawa Barat. Pemilihan lokasi penelitian ini dilakukan secara sengaja (purposive) dengan dasar pertimbangan bahwa lokasi tersebut merupakan salah satu sentra penghasil kripik pisang yang berada di Wilayah Bogor dan berproduksi secara kontinyu. Pengambilan data dilakukan pada bulan Mei sampai September 2012.

\section{Teknik Pengumpulan Data}

Metode pengumpulan data dilakukan dengan menggunakan data primer dan data sekunder. Data primer diperoleh melalui wawancara langsung dengan menggunakan kuesioner. Data primer diperoleh dari produsen Kripik Pisang "KREKES", dan data sekunder diperoleh jurnal, makalah seminar, majalah, catatan dan laporanlaporan dari pihak terkait lainnya.

\section{Metode Analisis Data}

Data yang diperoleh diolah dan dianalisis dengan dua cara yaitu secara kualitatif dan kuantitatif. Data kualitatif adalah data yang diperoleh dari hasil wawancara, dan dibuat dalam bentuk deskriptif, sedangkan data kuantitatif adalah data yang diperoleh dengan cara mengambil sampel dan diolah lalu menghasilkan hasil penelitian berupa angka-angka. Data kuantitatif diolah dengan menggunakan kalkulator dan disajikan dalam bentuk tabel, 
data kualitatif dijelaskan dalam bentuk uraian guna mendukung data kuantitatif. Analisis nilai tambah pisang untuk memproduksi keripik pisang menggunakan metode Hayami (1987) (Tabel 1)

Tabel 1. Prosedur Perhitungan Nilai Tambah Metode Hayami

\begin{tabular}{|c|c|}
\hline Variabel & Nilai \\
\hline \multicolumn{2}{|l|}{ I. Output, Input, dan Harga } \\
\hline 1. Output $(\mathrm{Kg}) /$ proses produksi & (1) \\
\hline 2. Input $(\mathrm{Kg}) /$ proses produksi & (2) \\
\hline 3. Tenaga Kerja $(\mathrm{HOK}) /$ proses produksi & (3) \\
\hline 4. Faktor Konversi & $(4)=(1) /(2)$ \\
\hline 5. Koefisien Tenaga Kerja (HOK) & $(5)=(3) /(2)$ \\
\hline 6. Harga Output $(\mathrm{Rp} / \mathrm{Kg})$ & (6) \\
\hline 7. Upah Tenaga Kerja Langsung (RP/HOK) & (7) \\
\hline \multicolumn{2}{|l|}{ II. Penerimaan dan Keuntungan } \\
\hline 8. Harga Bahan Baku (Rp/Kg) & (8) \\
\hline 9. Sumbangan Input Lain $(\mathrm{Rp} / \mathrm{Kg})$ & (9) \\
\hline 10. Nilai Output (Rp/Kg) & $(10)=(4) \times(6)$ \\
\hline 11. a. Nilai Tambah $(\mathrm{RP} / \mathrm{Kg})$ & $(11 a)=(10)-(9)-(8)$ \\
\hline b. Rasio Nilai Tambah (\%) & $(11 b)=(11 a) /(10) \times 100 \%$ \\
\hline $\begin{array}{l}\text { 12. a. Pendapatan Tenaga Kerja langsung } \\
(\mathrm{Rp} / \mathrm{Kg})\end{array}$ & $(12 a)=(5) \times(7)$ \\
\hline b. Pangsa Tenaga Kerja (\%) & $(12 b)=(12 a) /(11 a) \times 100 \%$ \\
\hline 13. a. Keuntungan $(\mathrm{Rp} / \mathrm{Kg})$ & $(13 a)=(11 a)-(12 a)$ \\
\hline b. Tingkat Keuntungan $(\%)$ & $(13 b)=(13 a) /(11 a) \times 100 \%$ \\
\hline \multicolumn{2}{|l|}{ III. Balas Jasa Pemilik Faktor-Faktor Produksi } \\
\hline 14. Marjin (Rp/Kg) & $(14)=(10)-(8)$ \\
\hline a. Pendapatan Tenaga Kerja Langsung (\%) & $(14 a)=(12 a) /(14) \times 100 \%$ \\
\hline b. Sumbangan Input Lain (\%) & $(14 b)=(9) /(14) \times 100 \%$ \\
\hline c. Keuntungan Pemilik Perusahaan & $(14 c)=(13 a) /(14) \times 100 \%$ \\
\hline
\end{tabular}

Sumber : Hayami (1987)

\section{HASIL DAN PEMBAHASAN Keragaan Perusahaan Krekes}

Industri rumah tangga Krekes adalah usaha sampingan dimana usaha utama yang dilakukan yaitu sebagai pedagang pisang (pengumpul) yang bertempat di pasar Anyar, Bogor. Dalam perkembangannya berpeluang dalam bisnis produk olahan yaitu keripik pisang Krekes.

Pada awal berdirinya industri makanan olahan Krekes ini mendapat bantuan pinjaman modal usaha dari DPU (Dompet Peduli Umat) sebesar Rp.
1.000.000, dengan pengembalian sebesar Rp. 50.000/minggu, dan juga masuk sebagai anggota pengajian di DPU sendiri. Dalam awal pemasarannya industri Krekes hanya memasarkan dilingkungan sekitar, koperasi pasar bogor, untuk lingkungan sekitar dijual per Ons dengan harga Rp. 2000. Sedangkan untuk koperasi dijual 1/4 kg dengan harga Rp. 6000. Untuk meningkatkan pendapatan maka harus memperluas pemasaran, meningkatkan produksi, melihat kepercayaan konsumen dan pada tahun 1998 Ibu Idjah mendapatkan izin Dinkes, dengan 
izin Dinkes ibu Idjah menambah produksi serta memperluas pemasarannya.

Bahan baku yang digunakan dalam memproduksi keripik pisang, yaitu pisang nangka yang dibeli langsung dari produsen di Lampung. Pemilihan pisang nangka sebagai bahan baku pembuatan keripik pisang yaitu karena sifat dari pisang tersebut cocok sebagai bahan baku, karena setelah pisang kepok langka serta harganya mahal dipasaran maka para pengusaha industri keripik pisang menggunakan bahan baku keripik pisang yaitu pisang nangka. Minyak goreng, gula pasir, masako, garam, merupakan bahan penolong utama yang diperlukan. Penggunaan masako,gula pasir, merupakan bahan penyedap bagi keripik pisang.

\section{Analisis Nilai Tambah Usaha Keripik Pisang Krekes \\ Analisis nilai tambah berguna untuk} menguraikan proses produksi menurut sumbangan masing-masing faktor produksi serta untuk mengetahui distribusi nilai tambah terhadap tenaga kerja langsung dan pengusaha. Nilai tambah pengolahan pisang menjadi keripik pisang dihitung berdasarkan metode analisis nilai tambah menurut Hayami pada Tabel 2.

Dari hasil perhitungan nilai tambah pada Tabel 2 diketahui bahwa hasil produksi/output untuk satu kali proses produksi sebesar $50 \mathrm{~kg}$ dari penggunaan bahan baku/input sebesar $200 \mathrm{~kg}$. Bahan baku yang digunakan disini adalah pisang nangka yang diukur dalam satuan $\mathrm{kg}$.

Tenaga kerja yang dihitung pada penelitian ini adalah semua tenaga kerja yang berperan dalam proses produksi keripik pisang yang berjumlah 3 orang pada perusahaan Krekes. Faktor konversi merupakan hasil bagi antara produksi/output dengan jumlah bahan baku/input yang digunakan, besarnya faktor konversi pada perhitungan di atas adalah sebesar 0,25, berarti setiap $\mathrm{kg}$ bahan baku menghasilkan $0,25 \mathrm{~kg}$ keripik pisang.

Koefisien tenaga kerja merupakan hasil bagi antara tenaga kerja dengan jumlah bahan baku yang digunakan dalam proses produksi. Besarnya nilai koefisien tenaga kerja pada perusahaan Krekes koefisien tenaga kerja sebesar 0,015 yang berarti untuk mengolah $100 \mathrm{~kg}$ bahan baku /input dibutuhkan tenaga kerja sebanyak 1,6.

Keuntungan perusahaan Krekes cukup besar karena dari jumlah bahan baku, tenaga kerja dan nilai tambah merupakan faktor yang mempengaruhi dan mendapatkan tingkat keuntungan 85,74 persen dengan nilai keuntungan sebesar Rp.2.255.

Tabel 2. Analisis Nilai Tambah keripik pisang pada perusahaan Krekes

\begin{tabular}{lc}
\hline \multicolumn{1}{c}{ Variabel } & Nilai Tambah \\
\hline I. Output, Input, dan Harga & 50 \\
1. Output $(\mathrm{Kg})$ & 200 \\
2. Input $(\mathrm{Kg})$ & 3 \\
3. Tenaga Kerja (HOK) & 0,25 \\
4. Faktor Konversi & 0,015 \\
5. Koefisien Tenaga Kerja (HOK) & 25.000 \\
6. Harga Output (Rp/Kg) & 25.000 \\
7. Upah Tenaga Kerja Langsung (RP/HOK) & \\
II. Penerimaan dan Keuntungan & 2000 \\
8. Harga Bahan Baku (Rp/Kg)
\end{tabular}




\begin{tabular}{lc}
\hline \multicolumn{1}{c}{ Variabel } & Nilai Tambah \\
\hline 9. Sumbangan Input Lain $(\mathrm{Rp} / \mathrm{Kg})$ & 1620 \\
10. Nilai Output $(\mathrm{Rp} / \mathrm{Kg})$ & 6250 \\
11. a. Nilai Tambah (RP/Kg) & 2630 \\
b. Rasio Nilai Tambah (\%) & 42,08 \\
12. a. Pendapatan Tenaga Kerja langsung (Rp/Kg) & 375 \\
b. Pangsa Tenaga Kerja (\%) & 14,25 \\
13. a. Keuntungan (Rp/Kg) & 2255 \\
b. Tingkat Keuntungan (\%) & 85,74 \\
III. Balas Jasa Pemilik Faktor-Faktor Produksi & \\
14. Marjin (Rp/Kg) & 4250 \\
d. Pendapatan Tenaga Kerja Langsung (\%) & 8,82 \\
e. Sumbangan Input Lain (\%) & 38,11 \\
f. Keuntungan Pemilik Perusahaan & 53,05 \\
\hline
\end{tabular}

\section{KESIMPULAN DAN IMPLIKASI KEBIJAKAN}

\section{Kesimpulan}

1. Besarnya nilai tambah industri keripik pisang pada perusahaan Krekes adalah sebesar Rp.2.630

2. Tingkat keuntungan 85,74 persen dengan nilai keuntungan sebesar Rp.2.255.

\section{Implikasi Kebijakan}

1. Dalam pengadaan bahan baku lebih memperluas kerjasama, agar dapat menjaga kontinuitasnya.

2. Pengolahan kripik pisang sedapat mungkin dijaga kualitasnya.

3. Untuk penelitian selanjutnya peneliti dapat meneliti kesempatan tenaga kerja dan manfaat sosialnya.

\section{DAFTAR PUSTAKA}

Badan Pusat Statistik. 2011. Klasisfikasi Pengelompokkan Usaha di Indonesia. Jakarta

Baharsjah, Syarifuddin, 1993.Hortikultura Sebagai Sumber Pertumbuhan BaruSektor Pertanian, (Agroindustri Buah-Buahan).Insanmitra

Satyamandiri.Jakarta.
Dirjen Industri Kecil dan Menengah. 2007. "Laporan Akhir Kajian Pengembangan Kompetensi Inti Daerah Kabupaten Bogor”. Bogor.

Foragri.Wordpress.Com/2011/06/23/. prospek-agroindustri-keripik-pisang

Hayami, Y. et al. 1987. Agricultural marketing and processing in upland Java. A perspective from a Sunda village. Bogor: CGPRT Centre.

Hidayat, Mohamad S.2010. Rencana Startegs Kementrian Perindustrian Tahun 2010-2014. Menteri Perindustrian Republik Indonesia. Jakarta.

Hidayat, Riyan. 2009. Analisis Nilai Tambah Pisang Awak (Musa paradisiaca, L) dan Distribusinya Pada Perusahaan "NA RASEUKI dan "BERKAH”di kabupaten Bireun, Aceh. Skripsi. Jurusan Manajemen Agribisnis, Fakultas Pertanian.Institut Pertanian Bogor, Bogor.

Maimun. 2009. Analisis Pendapatan Usahatani Dan Nilai Tambah Saluran Pemasaran Kopi Arabika Organik Dan Non Organik (Studi Kasus Pengolahan Bubuk Kopi Ulee Kareng di Banda Aceh. Skripsi. Jurusan Manajemen Agribisnis, Fakultas 
Pertanian Institut Pertanian Bogor, Bogor.

Parulian Ramaijon P. 2002. Analisis Pendapatan dan Nilai Tambah pada Industri KecilTapioka (Kasus Desa Ciparigi Bogor Utara). Institut Pertanian Bogor. Bogor.

PIPIMM, 2012. Pusat Informasi Produk Industri Makanan dan Minuman. Jakarta.

Rahardjo, M Dawam. 1986. Transformasi Pertanian, Industrialisasi dan Kesempatan Kerja. Universitas Indonesia Press.Jakarta

Satuhu, Suyanti dan Ahmad Supriyadi, 1994. "PISANG” budidaya, pengolahan dan prospek pasar. Penebar Swadaya. Jakarta.

Soekartawi. 2000. Agroindustri Dalam Persepktif Sosial Ekonomi. Raja Grafindo Persada. Jakarta
Soeharjo, A. 1991. Konsep dan Ruang Lingkup Agroindustri kumpulan makalah Agribisnis. Jurusan Sosial Ekonomi Pertanian. Institut Pertanian Bogor

Susilowati, Sri Hery. 2007. Peran Serta Agroindustri Dalam Perekonomian NasionaldanPendapatan Rumah Tangga Pertanian. Prosiding Seminar Nasional.Bogor.

Tunggadewi, Andini. 2009. Analisis Profitabilitas Serta Nilai Tambah Usaha Tahu dan Tempe.(Studi Kasus di Kecamatan Tegal Gundil dan Cilendek Timur Kota Bogor).Skripsi. Departemen Agribisnis, Fakultas Ekonomi dan Manajemen.Institut Pertanian Bogor. Bogor 